\title{
Women Age at First Birth and Knowledge of Family Planning Methods in Yoruba Society, Nigeria
}

\author{
John Lekan Oyefara, Phd \\ Department Of Sociology, Faculty Of Social Sciences, University Of Lagos, Akoka, Yaba, \\ Lagos, Nigeria \\ E-Mail: Oyefara@ Yahoo.Com, Loyefara@Unilag.Edu.Ng
}

Accepted: August 12, 2012 Published: September 16, 2012

Doi:10.5296/jsr.v3i2.2394 URL: http://dx.doi.org/10.5296/jsr.v3i2.2394

\begin{abstract}
This article investigates the relationships that exist between women age at first birth and knowledge of family planning methods in Yoruba society, Nigeria. This central objective was based on the identified and documented benefits associated with the adoption of family planning devices by women globally. Family planning programmes are integral and central parts of safe motherhood initiatives and maternal health programmes of the United Nations. The understanding of interrelationship between women age at first birth and family planning variables is of direct relevance to health planners and policymakers attempting to control population variables and encourage safe motherhood in Yoruba society. To achieve the central objective of the study, quantitative data were generated from 1,000 women in one of the six Yoruba speaking States in Nigeria: Osun State. A multi-stage random sampling technique was adopted to select the respondents, while simple percentages and chi-square statistical method of analysis were adopted to analyze generated data. Findings of the study show significant relationships between women age at first birth and family planning variables at $P<0.01$. Specially, adolescent mothers exhibit significant low level of knowledge, ever use and current use of family planning methods compared with older mothers. On the basis of the findings, it has been recommended that State governments, local and international non-state actors working on safe motherhood in Yoruba society need to reach adolescent mothers in-and-outside health institutions through community health workers with contraceptive methods messages and services in order to improve maternal health and reduce high population growth rate in Yoruba society.
\end{abstract}

Keywords: Women Age at First Birth, Family Planning Methods, Safe Motherhood, Yoruba, Nigeria.

\section{Introduction}

Family planning involves a conscious effort by couple to limit or space the number of 
children they want to have through the use of contraceptive methods. It also refers to the steps, practices and techniques adopted to determine, influence or decide when to have children (Mischell, 2007; NPC, 2009). The term is sometimes used synonymously with birth control, i.e. to have children according to plan (Akin, 2007). It has been demonstrated that family planning benefits the health and well-being of women throughout the world. Using contraception, which is an integral part of family planning, can help to avoid unwanted pregnancies and space birth. Some contraceptive methods are capable of playing the dual role of both preventing pregnancies as well as protect against STDs, including HIV/AIDS, and provide other health benefits (Bloom and Canning, 2003). As noted by Isiugo-Abanihe (1996:105) "family planning saves lives. It enables couples to decide for themselves when to have their children as well as how many children to have. By helping women bear their children during healthiest times for both mother and baby, family planning helps to prevent deaths of infants, children and mothers. The use of family planning allows women to avoid unwanted pregnancies, dangerous illegal abortions, and childbearing under circumstances that will threaten their infants' lives and their health. Thus, modern family planning is beneficial even though it remains a controversial issue".

The term birth control is said to have been coined by Margaret Sanger (1879-1966), a young American nurse in the first decade of $20^{\text {th }}$ century (Guttmacher, 1969). Sanger was said to have been disturbed by the numerous deaths faced by women who wanted to avoid childbirth through induced abortion, as well as slow death women suffer from too many pregnancies. Against oppositions from church and state at the time, Sanger rose to start a movement that would give women control over their body and sexuality. During this period, birth control and fertility were seen as entirely women's problem, so, men were hardly involved. It was the efforts of people like Sanger that brought the issue of family planner to public recognition as a vital component of human life. However, literature reveals that attempts at regulating births dates back to pre-Sanger period. As early as 1789, Thomas Robert Malthus, an English clergyman and college professor had started sounding warning about the implication of rapid population increase in his essay "The Principle of Population" (Weeks, 2002: 86). By that warning, Malthus was echoing the need for family planning and birth control; even though he did not use the terms. He enjoined his listeners to exercise "moral restraints" (an equivalent term for periodic abstinence) to check overpopulation. Furthermore, according to Akin (2007), ancient historical records indicate that humans have always sought means to control fertility through earlier methods. These earlier methods are generally referred to as Folk Methods, and some of them still persist till date. They include: withdrawal method, abstinence, douche method and vaginal sponge (Akin, 2007; Guttmacher, 1969).

In the above introduction, it is clear that family planning is a means by which individuals or couples space the process of conception, pregnancy and childbirth at intervals mutually determined by both husband and wife in order to have the desired number of children that they can conveniently maintain. Family planning also assists couples who have difficulties in having children to have the expected number of children they desired (Delano, 1988). In the contemporary world, family panning can be achieved by birth control methods. Specifically, 
birth control can be defined as both spacing and limiting the number of children. Birth control also refers to infertility therapy which allows childless women to have their desired number of children. In modern times, birth control is popularly associated with contraception and the desired number of children is determined by various social, cultural and economic factors. Against this background, this study seeks to provide answers to the following research questions: what is the current knowledge of family planning methods in Yoruba society? Does age at first birth affect the knowledge, ever use and current use of family planning methods in the study location? What method of family planning is more prevalent in Yoruba society? In the next section, various studies in the areas of family planning were carefully and thoroughly reviewed.

\section{Literature Review}

Contraception as a concept can also be defined as means of controlling fertility by using various methods that prevent conception. These methods can be traditional or modern. Traditional methods include: withdrawal method, abstinence, douche method and vaginal sponge (Akin, 2007; Guttmacher, 1969). Withdrawal method, also referred to as coitus interruptus (Isiugo-Abanihe, 2003), is probably the oldest technique which couples adopted in order to avoid having children. It refers to the withdrawal of the penis from the woman's vagina just prior to ejaculation so that the semen is deposited outside of the genital tract. The method is said to have been well known even before the time that the first book of the Old Testament, Genesis was written, about 1500 B.C. This establishes the antiquity of family planning habits (Akin, 2007; Guttmacher, 1969).

In Europe, particularly Western and Northern Europe, where relatively late marriage have been customary at all social levels (Bloom and Canning, 2003; Guttmacher, 1969), it appears that withdrawal was the principal method by which pregnancy was prevented in premarital love affairs (Dixon-Mueller, 1993). In America, Bloom and Canning (2003) reveals that about five couple out of a hundred use coitus interruptus as their main method of birth control. No side effect had been recorded except that some authors (e.g. Tsui and Burke, 2010) stress that the method can cause some men to ejaculate prematurely; and women are slow to achieve orgasm; therefore, pre-ejaculatory withdrawal by the male gives female less than normal opportunity to have orgasm which causes congestion of blood on pelvic organs, resulting in chronic pelvic pain. The absence of any substantial body of evidence to support these claims makes it difficult to assess. Authors like Guttmacher (1969) believe that this claim might have stemmed from dislike of withdrawal method than from scientific evidence. The cause of failure in this technique is reluctance by the man to withdraw before ejaculation.

Another oldest method is the Douche. It consists of flushing out the vagina with water after sexual intercourse in an effort to prevent pregnancy by removing semen. If the semen can be washed out of the vagina before any sperm have a chance to enter the womb, pregnancy will not occur. Literature reveals that the douche is relied on by about $6 \%$ of American couples and also popular in many parts of Europe (Bell, 1992). It is however rated as poor in 
effectiveness. The other is Vaginal Sponge. This involves the plugging of the upper vagina before intercourse by leaves or other barriers. This technique is said to have been in existence before the birth of Christ (Tsui and Burke, 2010). Natural sea sponges have been used as vaginal plugs for hundreds of years. Finely grained rubber bath sponges have been substituted for them recently. A piece of sponge one-half to three-quarters of an inch thick and two to three inches in diameter is cut out and a string tied to one edge. A spermicidal substance is rubbed on the moistened sponge to create lather before insertion into the vagina (Bell, 1992).

Beyond the so-called traditional methods, Sanhueza (2007) notes that the late 1950s through early 60s witnessed the emergence of modern contraceptive methods. In 1958, the first oral contraceptive pill was tested and subsequently introduced in May 1960. Before then however, a German physician, Ernest Graefenberg, had developed the intrauterine device (IUD) in 1929 (Sanhueza, 2007); but the knowledge of the existence of IUD was limited to a few countries in Europe and America.

Other modern medical advances in family planning include surrogacy and sperm donor. In surrogacy, a woman agrees to become pregnant and deliver a child for another couple or person. There are two types of surrogacy: Traditional Surrogacy and Gestational Surrogacy. In traditional surrogacy, a woman uses her own eggs and carries the child for her intended parents. This type involves a genetic connection between the surrogate and the child. On the other hand, a gestational surrogacy occurs when the intended mother's or a donor egg is fertilized outside the body and then the embryos are transferred into the uterus. The woman who carries the child is often referred to as a gestational carrier (Tsui and Burke, 2010). The method is not popular in Africa, but records show that is a common practice in some parts of India, and now a preferred destination to many North American women who patronize the system (Bhagat, 2004).

In sperm donor, pregnancies are usually achieved by using donated sperm through artificial insemination (either by intracervical insemination or intrauterine insemination) and less commonly by Invitro fertilization (IVF), usually known in this context as Assisted Reproductive Technology (ART). Insemination may also be achieved by a donor having sexual intercourse with a woman for the sole purpose of initiating conception. This method is known as natural insemination (Tsui et al, 2010). Agigian (2010) notes that there is a generally a demand for sperm donors who have no genetic problems in their family, 20/20 eyesight, with excellent visual acuity and sometimes, a value on a certain height and age.

\section{Current Use of Contraceptive Methods in Nigeria}

Information on current use of contraceptive methods, from NDHS (2008), shows that the overall contraceptive prevalence among all women in Nigeria is $15 \%$. The use of any family planning method increases with age from 7\% among women age 15-19 to 20\% among women age 35-39, and then declines to $10 \%$ among women age 45-49. Most women currently using contraception use a modern method (11\%), while 5\% are using traditional 
methods. The male condom is the most commonly used modern method (5\%), followed by the injectable and pills ( $2 \%$ for each); while IUD and female sterilization are the least used modern methods (less than one percent). Among the traditional methods, the rhythm method and withdrawal are the most commonly used (2\% each) (NPC, 2009:69). Among currently married women, existing literature shows that the most commonly used method in the injectables (3\%), followed by the male condom (2\%), while the rhythm method is the most commonly used traditional method (2\%). Among sexually active unmarried women, the most commonly used modern method is the male condom (35\%), followed by the pill (4\%); while the rhythm method and folk methods are the most widely used traditional methods (7\%). At the zonal level, current use of any modern method among currently married women according to zones in Nigeria includes: North Central (11\%), South-East (4\%), North-West (3\%), South-East (12\%), South-South (16\%) and South-West $(21 \%)$. The data reveal a generally low level of use of modern contraception in the North, especially North-East and North West. This might be indicative of why these zones have the highest fertility rates in the country. For instance, TFR in North-West is 7.3 children per woman; North-East is 7.2 children per woman. Compare this with South-West (4.5), South-South (4.7) and South-East (4.8) (NPC, 2009).

\section{Adolescents And Use Of Contraceptive Methods}

While knowledge about family planning services is now more widespread in Nigeria, its usage is very low among adolescent girls. Several studies in the past three-decades confirm the low usage of contraception among adolescents in Nigerian societies. For instance, the National Fertility Survey (1982/83) shows that only 3.5 percent of adolescents had used at least one efficient method of contraception in early 1980s (NPB/WFS, 1984). Nearly a decade later and after the official adoption of a national population policy to curtail child bearing, the 1990 Nigerian Demographic and Health Survey (NDHS) reveals that only 4 percent of girls in the age group 15-19 had ever used a modern method of contraception (FOS, 1992). The 1999 NDHS also corroborates the low usage of contraception among adolescent girls in Nigeria as reported in the first two national surveys. According to the reports of this current national demographic survey, only 5.9 percent of adolescent girls in the age group 15-19 had ever used a modern method of contraception, while just only 3.2 percent of girls in this age group are currently using any of the modern methods (NPC, 2000).

Study on sexual behaviour of post secondary school students in Enugu State, Nigeria shows that all the respondents were sexually active, 51 percent of these students had never used a contraceptive method, and 76 percent had not used a method the first time they had intercourse; 60 percent of those who had ever used a method had first done so between the ages of 20 and 24 years. Some of the students reported using rhythm and barrier methods, and some had fears resulting from their misperceptions about contraception (Ozumba and Amaechi, 1992). In a study among adolescent girls in rural Nigeria, 70 percent did not know about contraception and only 10 percent could identify the monthly fertile period. Additionally, only 16 percent of 
adolescents in the sample were using contraceptives and more than 80 percent of those who were pregnant had not intended to conceive (Okonofua, 1995).

In a study among in-school adolescents in Nigeria, respondents were asked to name method of contraception they had ever used to avoid pregnancy; 15 percent of sexually active students reported having used condoms, 2 percent abstinence, 2 percent the pill and less than 1 percent the injectable. The pattern of ever-use was roughly the same regardless of students' characteristics. However, it was discovered that the proportion of SSS2 students who had used condoms was twice that among their SSS1 counterparts (19 percent versus 10 percent). Similar differences in condom use were found between urban and rural students (17 percent and 11 percent respectively), and between young men and young women (17 percent and 13 percent respectively) (Amazigo et al. 1997). The overall level of ever-use of a contraceptive was higher among students who engaged in relationships with multiple sexual partners (20 percent) than among those who had one partner (14 percent). Ever-use of condoms also was more prevalent among students who had multiple partners (19 percent) than among those with one partner (12 percent).

The rate of contraceptive use in Nigeria is considerably lower in relation to some other developing countries in other continents of the world. For example, data from Brazil show that 94 percent of women of reproductive age living in Union in 1996 used some method of family planning, and the vast majority of these women were using a modern contraceptive (Martine, 1996). Evidence from the 1996 Brazil DHS suggests that contraceptive usage is widespread among adolescents, with 72 percent of sexually experienced adolescent girls reporting in 1996 that they had ever used contraceptive, a striking increase from the rate 10 years earlier (55 percent) among this age group. Among sexually experienced adolescents, the pill is the most prevalent method ( 27 percent), followed by the condom (10 percent) (Gupta and Leite, 1999). Despite these relatively high levels of contraceptive use among adolescents in Brazil, an unmet demand for family planning services seems to persist. Data from the 1996 DHS in the country suggest that up to half of all births across the country are unplanned. In the Northeast, 51 percent of adolescents reported their last birth was unplanned. This marks a considerable increase from 40 percent in 1986, although birth spacing seems to be a greater issue among the teenagers than family-size limitation (Gupta and Leite, 1999).

In Nigeria, the use of condoms increased with age. Specifically, 9 percent of 15 years old adolescents who were sexually active did, and the proportion climbed to 27 percent among 19 years old respondents. Focus groups discussions and in-depth interviews about contraception yielded information concerning alternative methods of birth control used by adolescent in Nigeria. In interviews, adolescents mentioned commercial products such as liver salt, broad-spectrum antibiotics and a mixture of gin and akawu (sodium sesquicarbonate, which is used locally to tenderize breadfruit as contraceptive methods. Students described the gin mixture as a drink taken after sexual intercourse to "wash everything away". They also mentioned that young women often take liver salts to terminate pregnancy (Amazigo et al 1997). 
Particularly in sub-Saharan Africa and South Asia, young married women often face cultural expectations and social pressure to "prove" their childbearing abilities to their families and their husband's families immediately after the marriage (Mensch et al. 1998; Pachauri, 1996). As a result, few married adolescents use contraception. Conversely, sexually active young unmarried women have strong motivation to avoid pregnancy, and so they tend to use contraception (McCauley and Salter, 1995). In sub-Saharan Africa, married women between age 15 to 19 years have particularly low levels of contraceptive use, at about 13 percent. Among unmarried sexually active adolescents, however, the level of contraceptive use reaches 39 percent. In the region some 20 percent of married women between age 20 to 24 years use contraception compared with 49 percent of sexually active unmarried women in the same age group. Unmarried women most often use condoms, while married women most often use oral contraceptives or traditional methods (Zlider et al. 2003).

In Latin America and Caribbean an average of 39 percent of married women ages 15 to 19 use contraception. By comparison, 60 percent of sexually active unmarried women of this age group use contraception. Women ages 20 to 24 are even more likely to use contraception, at 52 percent of married women and 69 percent of sexually active unmarried women. Among married women, pills and injectables are the most widely used; among unmarried women, pills, condom, and traditional methods are predominant (Zlider et al. 2003). In Eastern Europe and Central Asia nearly 30 percent of married adolescents use family planning, mostly traditional methods. Eight (8) of every ten (10) unmarried sexually active adolescents use a family planning method; half use condoms. Among married women ages 20 to 24, IUDs and traditional methods are most used, while unmarried women in this age group rely on condoms as well as traditional methods (Zlider et al. 2003). The above comparable survey data show that contraceptive use prevalence rate is very low in sub-Saharan Africa than any other continent or region of the world. Consequently unwanted pregnancies and childbirths are very high among adolescent girls in the region.

Data on when adolescents normally start using contraceptive methods reveal the major reason why unwanted pregnancies are rampant among adolescents all over the world. Studies in U.S.A and other countries have found that women delay about one year on the average between starting sexual activity and first using modern contraceptives (AGI, 1994; CR, 1995; Kau et al. 1989). Thus premarital sexual activity often results in unintended pregnancy. In Mexico nearly two-thirds of women ages 18-19 with premarital sexual experience reported that they had been pregnant at least once (Morris, 1992). In a Zimbabwe study, 46 percent of premarital sexually active women ages 11 to 19 had been pregnant (Boohene et al. 1991). Many unplanned pregnancies occur within a year after first sexual intercourse (CR, 1995; Zabin et al. 1979). For example, of 200 16-year olds delivering at Harare Maternity Hospital, Zimbabwe, over one-half had become pregnant within just three months of starting sexual activity (Mahomed and Masona, 1991).

The most common reason that both young men and women give for not using contraception 
is that they did not expect to have intercourse. The second most common reason is that they did not know about contraception (Kiragu, 1991; Morris, 1992 McCauley and Salter, 1995). Young people often know little or have incorrect information about fertility and contraception. Young men are more likely than women to mention lack of knowledge and are much more likely to say that it is their partner's responsibility to avoid pregnancy (Barker and Rich, 1992; Berganza et al. 1989; Morris, 1992). Even when young people can name contraceptives, they often do not know where to get them or how to use them (Agyei and Epema, 1992). It has also been documented that when many young adolescents know about contraceptives, few use them because it is more difficult for adolescents to obtain contraceptives than it is for older, married couples. Often times, adolescents do not know where to go or what to expect. Many are unable to pay for services or for transportation to clinics (McCauley and Salter, 1995). Often, laws prohibit or limit providing contraceptives, services, or even information to young people (Daly et al. 1994; Paxman and Zuckerman, 1987). It has also been noted that even where access is not restricted by law, some family planning services have policies or prejudices against serving unmarried people. Rude or judgmental staff deter some young people from seeking contraceptives. For example, in a South African study young field workers posing as clients reported that personnel at some clinics resisted their requests for condoms and often provided no instructions on condom use (Abdoel-Karim et al. 1992).

Other contextual factors affecting contraceptive practices among adolescents are the extent of communication between partners, attitudes about social and sexual roles, and the taboo nature of sexual activity (Billy, et al. 1994). For example, young unmarried people may be even less likely to discuss contraception since in many cultures; sex-related issues are rarely discussed, even between spouses (McCauley and Salter, 1995). Many adolescents see contraception as something only for married adults who want to space their children (Schensul et al. 1993). Some men and some women themselves may disapprove of contraception because they believe it encourages women to be promiscuous (Berganza et al. 1989).

Contraceptive methods are not often used at the first intercourse as stated earlier mainly because of the belief that a girl cannot become pregnant the first time she has sex. For instance, Makinwa-Adebusoye in 1991 reported that 30 percent of male and female adolescents sampled in five major urban centres in Nigeria did not realize that the first intercourse could result in pregnancy, thus they do not use contraceptive methods to prevent unwanted pregnancy (Makinwa-Adebusoye, 1991). When adolescents use contraceptives at all, they often rely on traditional methods, which are less effective than the modern methods (FOS, 1992; NPC 2000). The most poignant issue about the high prevalence rate of sexual networking among the Nigerian adolescents is the low use of modern contraception most especially, the condom. Nationwide, the 1990 NDHS reports 5 percent of adolescents between 15-19 years old females as currently using any method of contraception; two-thirds of this proportion use traditional methods including rhythm or withdrawal which are ineffective. One percent use oral contraceptives, less than one percent use condoms, foaming tablets or IUDs (FOS, 1992). There is no significant difference in the levels of use of contraceptives in Nigeria 10 years after 1990 NDHS study except the relative increase in the 
use of condoms from 0.4 in 1990 NDHS to 3.5 in 1999 NDHS reports (NPC, 2000). In general, only 9.2 percent of adolescent women aged 15-19 were currently using contraceptive during the 1999 NDHS data-gathering period. Five percent of them were using the ineffective traditional methods (NPC, 2000). In addition, 2003 NDHS report shows general low rate of modern contraceptive methods among women in Nigeria. Specifically, the report reveals that 3.4 percent of all women sampled are using condom, 2.0 percent are using pills, while 1.6 percent are using injectables (NPC, 2004).

The reasons for the low contraceptives prevalence among adolescents in Nigeria may be due to lack of access to contraceptives or lack of adequate information, since many adolescents often know little or have incorrect information about contraceptives. A study of female students in Enugu, for example, shows that 61 percent of the respondents believed that contraceptives cause infertility (Ozumba and Amaechi, 1992). In a study of oral contraceptive use among female students, 92 percent were aware of the method, yet only 17.5 percent had ever used it (Adinma and Okeke, 1993). This implies that there is a wide gap between knowledge and practice of family planning methods among adolescents in Nigeria.

Another crucial effect of high sexual networking and low contraceptives use, particularly the use of condom, is a high possibility of contracting Sexually Transmitted Diseases (STDs) including infection with Human Immunodeficiency Virus (HIV), which results in AIDS. This means that the high rate of unprotected sexual networking among adolescents in Nigeria increase their risk of contracting STDs/HIV/AIDS. Since most adolescents are active sexually but lack adequate knowledge of the risks involved, they constitute the group that is highly vulnerable to HIV/AIDS pandemic. It should be noted also that STDs including HIV are more rampant in the developing nations including Nigeria due to the lack of education. Most of the adolescents do not receive family life education and hence, they are not aware of precautionary measures to adopt in order to prevent and protect themselves in sexual relationship/intercourse. Even in the event of getting in contact with any of these diseases, most adolescents do not know their symptoms, what to do next, or where else to go. Instead, they prefer to conceal it until it almost gets out of hand, or ask for advice from their peers who are just as ignorant as them. For instance, Focus Group Discussions in Nigeria revealed that some young people consider Cancer, Asthma, Smallpox, Polio, and Diabetes to be STDs. Some believe that STDs are transmitted by eating together and sharing of cooking utensils (Barker and Rich, 1992). In summary, empirical data from different parts of Nigeria show that modern contraceptive prevalence rate is grossly low across the country, coupled with high sexual networking identified in the country; unwanted pregnancies and childbearing are very high in the country. The next section of the article delves into the methodology adopted in the study.

\section{Research Methods}

\section{Research Design}




\section{Macrothink}

The research design adopted in the study is a non-experimental research design. In this design, a cross-sectional survey method was used to generate primary data in the study. The reason for this was to generate quantitative information concerning the topic under study. Thus the quantitative was geared toward identifying the mechanism by which age at first birth determines the knowledge, ever use and current use of family planning methods in Yoruba society of Nigeria.

\section{Yoruba Society: Study Location}

The Yoruba, largely located in the Tropical Rain Forest and Guinea Savanna Zones of coastal West Africa, are concentrated in Southwestern Nigeria otherwise known as Yoruba land. Presently, there six (6) Yoruba speaking States in the Federal Republic of Nigeria. These are Oyo, Ogun, Osun, Ekiti, Lagos, and Ondo. It is imperative to note that the Yoruba can also be seen in Kwara and Kogi State with other ethnic groups. The major subgroups of Yoruba include the Egba, Egbado, Ekiti, Igbomina, Ijebu, Ijesa, Kabba, Ondo, Owo, and Oyo. All these people speak a common language known as Yoruba. Demographically, about 30-35 million people speak Yoruba language making Yoruba to be one of the largest ethnic groups in Nigeria, constituting about $20 \%$ of the poplation (Oyefara, 2011). It is imperative to note that the subgroups of Yoruba mentioned above speak distinct dialects of Yoruba language. In addition, the Yoruba have several towns that are distinct from one another in terms of their migration origin, ancestral lineage and clan, and kinship institution. Each of these towns creates its own meaning in the wider Yoruba cosmos through festivals that are linked to myths, rituals, and religions.

\section{Study population, sample size and sampling method}

Out of the six (6) Yoruba speaking States in Nigeria, Osun State was randomly chosen for the study using simple random sampling method. The State was created on August 27, 1991. Osun State is composed of thirty (30) Local Government Areas (LGAs) during the time of survey. Two (2) LGAs out of the 30 LGAs in the State were randomly selected for the study with the aid of stratified random sampling system of sampling method. The procedures adopted here involved the stratification of the 30 LGAs into two main strata on the basis of rural/urban-characteristics of the Local Government Areas in the State. One LGA each was randomly selected from each stratum of the two strata. The two (2) LGAs selected are Osogbo LGA with headquarter in Osogbo the State capital of Osun State and Ola-Oluwa LGA with headquarter in Bode-Osi. Osogbo LGA represents the urban centres in the State. The 2006 Population Census figures show that the total population of this LGA was 115,507 in 2006 and its current estimated population is about 188,197 in 2012. Ola-Oluwa is purely a rural LGA. The local government is made up of one hundred and fifteen (115) rural communities, out of which 9 are major communities (NPC, 1998). Ola-Oluwa LGA had a total population of 76,227 people in 2006 and the current estimated total population of the LGA is about 92,251 in 2012. The LGA represents the rural communities in Osun State for the study. 
The study population of the survey are women within the child bearing age (15-49 years) with at least a live birth as at the time of survey. A multistage random sampling technique was utilized to select the respondents in the Survey. The non-existence of a sampling frame (i.e. the list of all women within the childbearing age that posses the three features stated above in Osun State) necessitated the adoption of a multi-stage random sampling technique in the survey exercise. SPSS software package (version 10.0) was used to survey data after returned questionnaires had been thoroughly screed and edited to eliminate all possible errors. Percentages, means, Pearson Chi-squares and contingency coefficients were the statistical methods used in the interpretation of quantitative data.

\section{Findings}

\section{Age At First Childbirth And Knowledge Of Family Planning Methods}

The 1990 Nigeria Demographic and Health Survey (NDHS) provides us with the first detailed national and comparable data on the knowledge and prevalence of family planning methods in the country. The NDHS data show that knowledge of family planning methods witnessed a remarkable improvement between 1981 and 1990 because about 46 percent of all women aged 15-49 at the time of the study in 1990 knew at least one method of family planning, with about 44 percent identifying modern methods of which the pill, injection, condom, IUCD and female sterilization were most commonly known (FOS, 1992).

The 2003 NDHS results also confirmed the relative improvement in knowledge of family planning methods in Nigeria. Knowledge of these family planning methods experienced more than 100 percent increase between 1981 and 1990. In addition, the knowledge of family planning methods increased from 45.7 percent in 1990 to 65.4 percent in 1999 and 78.5 percent in 2003 among all women interviewed in the country (FOS, 1992; NPC, 2000; 2004). In fact, the 2003 NDHS report shows 76.7 percent of the respondents have knowledge of any modern family planning method (NPC, 2004:62). This recent improvement in knowledge of modern planning methods may be related, at least in part, to the National Population Policy which was first launched in Nigeria in 1985 (FRN, 1988). The policy has tended to give legitimacy to family planning through widespread discussion and communication in the media, hospitals and clinics and even in civic activities (Isiugo-Abanihe, 1996:113).

Table 1 shows that older mothers had relatively better knowledge about methods of family planning methods than adolescent mothers in Osun State, Nigeria. Specifically, 94.0 percent of older mothers as against 83.2 percent among adolescent mothers had knowledge about methods of family planning in the study area. Those respondents that have knowledge about family planning methods were asked to mention the one they know very well. Using the first method mentioned by the respondent, responses to this question can be seen on Table 1. Data on the table show relatively poor knowledge among adolescent mothers in relation to older mothers in all methods mentioned except knowledge on condom and finger ring (a traditional 
method) which many adolescent mothers mentioned more than older mothers.

An analysis of the relationship between age at first childbirth and knowledge of family planning method shows that age at first childbirth has effects on knowledge of family planning in Osun State, Nigeria. This relationship was significant at 0.01 level of significance. The degree of the relationship between the two variables as revealed by Contingency Coefficient was 0.164 . This means that about 16.0 percent of differences in knowledge of family planning methods can be explained by age at first childbirth. The proportion of adolescent mothers who could mention a method of family planning was considerably lower compared to older mothers for all methods mentioned except in condom and fingers rings (a traditional method) where adolescent mothers showed higher knowledge than older mothers. Specifically, older mothers have better knowledge of most of the effective methods of family planning such as pills, IUCD, and injection, but adolescent mothers' knowledge of these three methods is very low.

Table 1: Percentage distribution of respondents showing the relationship between age at first birth and knowledge of family planning methods

\begin{tabular}{|c|c|c|c|c|c|c|}
\hline \multirow[t]{2}{*}{$\begin{array}{l}\text { Knowledge of family planning } \\
\text { methods }\end{array}$} & \multicolumn{2}{|c|}{$\begin{array}{l}\text { Adolescent } \\
\text { mothers }\end{array}$} & \multicolumn{2}{|c|}{$\begin{array}{l}\text { Older } \\
\text { mothers }\end{array}$} & \multicolumn{2}{|l|}{ Total } \\
\hline & No & $\%$ & No & $\%$ & No & $\%$ \\
\hline $\begin{array}{l}\text { Do you know any of the family } \\
\text { methods? } \\
\text { Yes } \\
\text { No } \\
\text { Total } \\
\mathbf{X}^{2}=\mathbf{2 8 . 5 9 0} \\
\text { d.f. }=\mathbf{1}, \mathrm{C}=\mathbf{0 . 1 6 4 ,} \mathrm{P}=\mathbf{0 . 0 0 0}\end{array}$ & $\begin{array}{l}416 \\
84 \\
\mathbf{5 0 0}\end{array}$ & $\begin{array}{l}83.2 \\
16.8 \\
\mathbf{1 0 0 . 0}\end{array}$ & $\begin{array}{l}470 \\
30 \\
\mathbf{5 0 0}\end{array}$ & $\begin{array}{r}94.0 \\
6.0 \\
\mathbf{1 0 0 . 0}\end{array}$ & $\begin{array}{r}886 \\
114 \\
\mathbf{1 0 0 0}\end{array}$ & $\begin{array}{r}88.6 \\
11.4 \\
\mathbf{1 0 0 . 0}\end{array}$ \\
\hline $\begin{array}{l}\text { Mention the one you know (first } \\
\text { method mentioned) }\end{array}$ & & & & & & \\
\hline Pills & 115 & 23.0 & 199 & 39.8 & 314 & 31.4 \\
\hline IUCD/Copper T & 29 & 5.8 & 51 & 10.2 & 80 & 8.0 \\
\hline Injectable & 26 & 5.2 & 32 & 6.4 & 58 & 5.8 \\
\hline Condom & 179 & 35.8 & 114 & 22.8 & 293 & 29.3 \\
\hline Abstinence & 2 & 0.4 & 3 & 0.6 & 5 & 0.5 \\
\hline Safe Period/Rhythm & 6 & 1.2 & 9 & 1.8 & 15 & 1.5 \\
\hline Withdrawal & 3 & 0.6 & 16 & 3.2 & 19 & 1.9 \\
\hline Finger Ring & 53 & 10.6 & 40 & 8.0 & 93 & 9.3 \\
\hline Waist Band & 3 & 0.6 & & 1.2 & 9 & 0.9 \\
\hline No Knowledge & 84 & 16.8 & 6 & 6.0 & 114 & 11.4 \\
\hline Total & 500 & 100.0 & 30 & 100.0 & 1000 & 100.0 \\
\hline
\end{tabular}


500

\section{Age At First Childbirth And Ever Use Of Family Planning Methods}

Table 2 reveals that out of all the methods of family planning methods mentioned by the respondents in Table 1, a much smaller proportion of adolescent mothers compared with older mothers reported ever used of any of the family planning methods mentioned, except finger ring (a traditional method). The Low levels of modern contraceptive use among adolescent mothers, despite their widespread knowledge about these methods, may reflect lack of interest in the use of family planning methods among adolescents in the study area, especially immediately after commencement of childbearing. The result of Chi-Square analysis on Table 2 shows that age at first childbirth was a significant factor that influences the use of contraceptive methods in Osun State, Nigeria. According to Table 2 below, about 70.6 percent of older mothers had ever used a method of contraception, while only 33.4 percent of adolescent mothers claimed to have ever used at least a method of contraception in their lifetime. This relationship between age at first childbirth and ever use of contraception was significant at 0.01 level of significance and the degree of the relationship was 0.348 which is very high. Data on specific methods of family planning ever used by adolescent mothers on Table 2 showed that condom had the highest frequency of 55 respondents constituting 11.0 percent of adolescent mothers.

Table 2:Percentage distribution of respondents showing the relationship between age at first birth and ever use of family planning methods

\begin{tabular}{|c|c|c|c|c|c|c|}
\hline \multirow[t]{2}{*}{$\begin{array}{l}\text { Ever use any of the family planning } \\
\text { methods }\end{array}$} & \multicolumn{2}{|c|}{$\begin{array}{l}\text { Adolescent } \\
\text { mothers }\end{array}$} & \multicolumn{2}{|c|}{$\begin{array}{l}\text { Older } \\
\text { mothers }\end{array}$} & \multicolumn{2}{|l|}{ Total } \\
\hline & No & $\%$ & No & $\%$ & No & $\%$ \\
\hline $\begin{array}{l}\text { Have you ever used any of the family } \\
\text { methods? } \\
\text { Yes } \\
\text { No } \\
\text { Total } \\
X^{2}=138.606 \\
\text { d.f. }=\mathbf{1}, \mathrm{C}=\mathbf{0 . 3 4 8 , P = 0 . 0 0 0}\end{array}$ & $\begin{array}{r}167 \\
333 \\
\mathbf{5 0 0}\end{array}$ & $\begin{array}{l}33.4 \\
66.6 \\
\mathbf{1 0 0 . 0}\end{array}$ & $\begin{array}{l}353 \\
147 \\
500\end{array}$ & $\begin{array}{l}70.6 \\
29.4 \\
\mathbf{1 0 0 . 0}\end{array}$ & $\begin{array}{r}520 \\
480 \\
\mathbf{1 0 0 0}\end{array}$ & $\begin{array}{r}52.0 \\
48.0 \\
\mathbf{1 0 0 . 0}\end{array}$ \\
\hline $\begin{array}{l}\text { Mention the one you commonly use } \\
\text { Pills } \\
\text { IUCD/Copper T } \\
\text { Injectable } \\
\text { Condom }\end{array}$ & $\begin{array}{l}28 \\
15 \\
10 \\
55\end{array}$ & $\begin{array}{r}5.6 \\
3.0 \\
2.0 \\
11.0\end{array}$ & $\begin{array}{r}94 \\
50 \\
25 \\
112\end{array}$ & $\begin{array}{c}18.8 \\
10.0 \\
5.0 \\
22.4\end{array}$ & $\begin{array}{r}122 \\
65 \\
35 \\
167\end{array}$ & $\begin{array}{r}12.2 \\
6.5 \\
3.5 \\
16.7\end{array}$ \\
\hline
\end{tabular}




\begin{tabular}{|l|r|c|l|r|r|r|}
\hline Abstinence & 2 & 0.4 & & 0.6 & 5 & 0.5 \\
Safe Period/Rhythm & 1 & 0.2 & 3 & 1.6 & 9 & 0.9 \\
Withdrawal & 3 & 0.6 & & 3.2 & 19 & 1.9 \\
Finger Ring & 52 & 10.4 & 8 & 8.0 & 92 & 9.2 \\
Waist Band & 1 & 0.2 & & 1.0 & & 0.6 \\
Never use & 333 & 66.6 & 16 & 29.4 & 6 & 48.0 \\
Total & $\mathbf{5 0 0}$ & $\mathbf{1 0 0 . 0}$ & & $\mathbf{1 0 0 . 0}$ & 480 & $\mathbf{1 0 0 . 0}$ \\
& & & 40 & & $\mathbf{1 0 0 0}$ & \\
& & & & & & \\
& & & 5 & & & \\
& & & $\mathbf{5 0 0}$ & & & \\
\hline
\end{tabular}

\section{Age At First Childbirth And Current Use Of Family Planning Methods}

Information on current use of contraceptive methods can be seen on Table 3 . The data on the table show that adolescent mothers consistently had low rates of current use in each of the contraceptive methods mentioned by the respondents during the survey. In particular, the rate of condom use among adolescent mothers ( 8.0 percent) was very low in comparison with its current use (21.2 percent) among older mothers in the State. Furthermore, 4.0 percent of adolescent mothers compared with 9.4 percent of older mothers were currently using oral pills, while 1.2 percent of adolescent mothers in relation to 4.0 older mothers stated that they were currently using injectables. The current use of IUCD/Copper T was also higher among older mothers in comparison with adolescent mother. Specifically, 7.2 percent of older mothers compared with 2.2 percent among adolescent were currently had ever used IUCD.

Table 3: Percentage distribution of respondents showing the relationship between age at first birth and current use of family planning methods.

\begin{tabular}{|c|c|c|c|c|c|c|}
\hline \multirow[t]{2}{*}{$\begin{array}{l}\text { Current use of any of the family } \\
\text { planning methods }\end{array}$} & \multicolumn{2}{|c|}{$\begin{array}{l}\text { Adolescent } \\
\text { mothers }\end{array}$} & \multicolumn{2}{|c|}{$\begin{array}{l}\text { Older } \\
\text { mothers }\end{array}$} & \multicolumn{2}{|l|}{ Total } \\
\hline & No & $\%$ & No & $\%$ & No & $\%$ \\
\hline $\begin{array}{l}\text { Are you currently using a method of } \\
\text { family methods? } \\
\text { Yes } \\
\text { No } \\
\text { Total } \\
\mathbf{X}^{2}=85.983 \\
\text { d.f. }=\mathbf{1}, \mathrm{C}=\mathbf{0 . 2 8 7}, \mathbf{P}=\mathbf{0 . 0 0 0}\end{array}$ & $\begin{array}{l}131 \\
369 \\
\mathbf{5 0 0}\end{array}$ & $\begin{array}{l}26.2 \\
73.8 \\
\mathbf{1 0 0 . 0}\end{array}$ & $\begin{array}{l}275 \\
225 \\
\mathbf{5 0 0}\end{array}$ & $\begin{array}{l}55.0 \\
45.0 \\
\mathbf{1 0 0 . 0}\end{array}$ & $\begin{array}{r}406 \\
594 \\
\mathbf{1 0 0 0}\end{array}$ & $\begin{array}{r}40.6 \\
59.4 \\
\mathbf{1 0 0 . 0}\end{array}$ \\
\hline $\begin{array}{l}\text { Mention the one you are currently } \\
\text { using }\end{array}$ & & & & & & \\
\hline
\end{tabular}




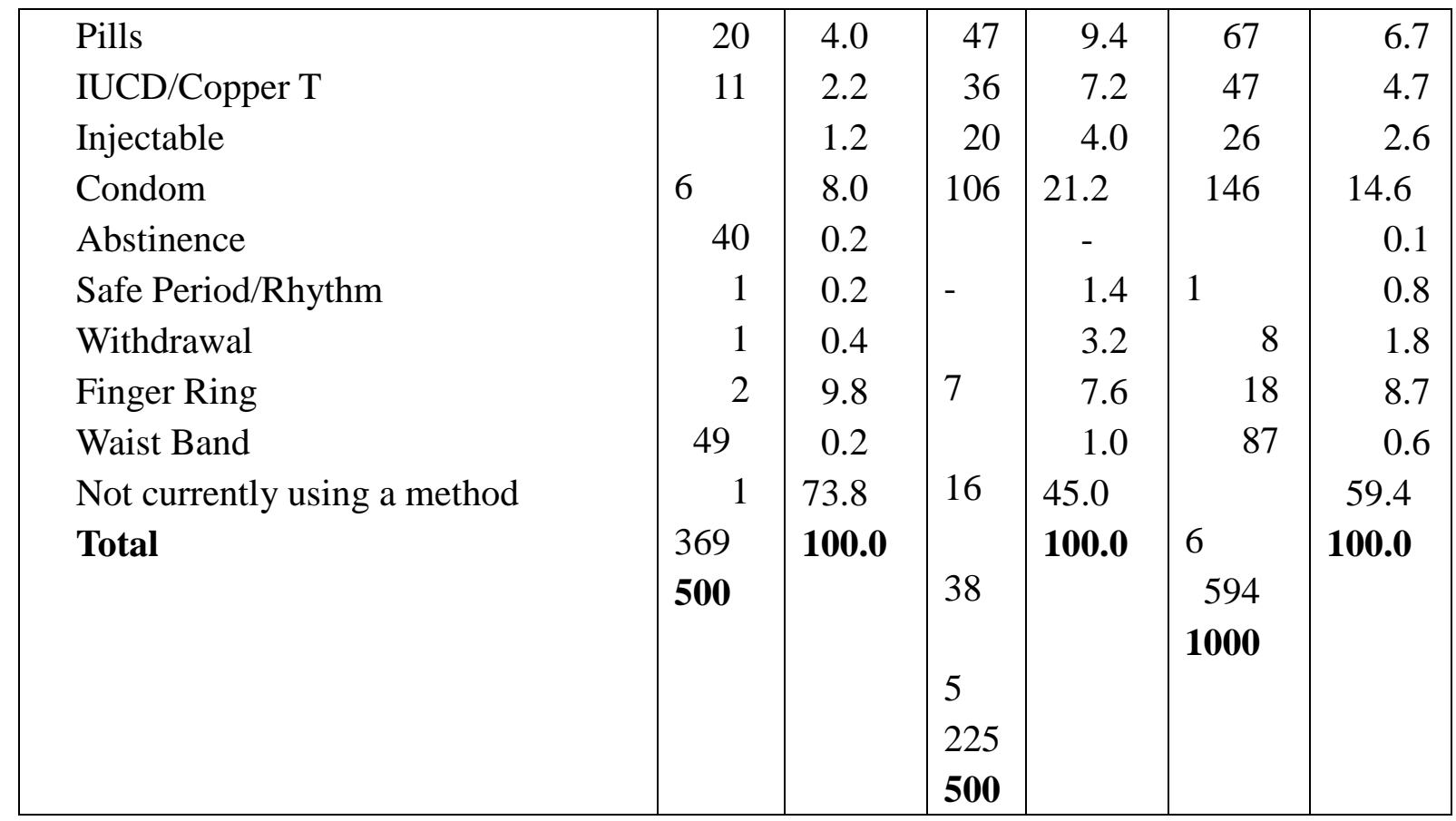

\section{Age At First Childbirth And Decision To Use Family Planning Method}

Women empowerment which has the features of economic and financial independence with educational advancement has been identified to play a significant role in a woman's decision to adopt a method of family planning. Adolescent mothers are usually financially dependent on their husbands and parents; consequently many of them may not be able to solely adopt a method of contraception (Oyefara, 2011). As can be seen in Table 4, among small proportion of adolescent mothers that were currently using at least a method of contraception 13.0 percent of them rely on instruction from their husbands/partners as against just 4.4 percent among older mothers. In addition the table shows that many of older mothers enjoyed more support from their husbands (72.0 percent) compared to 63.3 percent among adolescent mothers when it comes to decision on whether to use a method of family planning method or not.

Table 4:Percentage distribution of respondents showing the relationship between age at first birth and who decides on the use of method of family planning and attitude toward family planning method

\begin{tabular}{|l|l|l|l|l|l|r|}
\hline \multirow{2}{*}{ Variable } & \multicolumn{2}{|l|}{$\begin{array}{l}\text { Adolescent } \\
\text { mothers }\end{array}$} & \multicolumn{2}{l|}{$\begin{array}{l}\text { Older } \\
\text { mothers }\end{array}$} & \multicolumn{2}{l|}{ Total } \\
\cline { 2 - 8 } & No & $\%$ & No & $\%$ & No & $\%$ \\
\hline Who decides on the method of family & & & & & & \\
planning currently using? & & & & & & \\
$\quad$ Woman alone & 31 & 23.7 & 65 & 23.6 & 96 & 23.6 \\
Husband/Partner alone & 17 & 13.0 & 12 & 4.4 & 29 & 7.1 \\
\hline
\end{tabular}




\begin{tabular}{|c|c|c|c|c|c|c|}
\hline $\begin{array}{l}\text { Both } \\
\text { Total } \\
\mathbf{X}^{\mathbf{2}}=\mathbf{8 . 5 5 1} \\
\text { d.f. }=\mathbf{2}, \mathbf{C}=\mathbf{0 . 0 9 4 ,} \mathbf{P}=\mathbf{0 . 0 3 2}\end{array}$ & $\begin{array}{r}83 \\
131\end{array}$ & $\begin{array}{l}63.3 \\
\mathbf{1 0 0 . 0}\end{array}$ & $\begin{array}{l}198 \\
275\end{array}$ & $\begin{array}{l}72.0 \\
100.0\end{array}$ & $\begin{array}{l}281 \\
406\end{array}$ & $\begin{array}{r}69.2 \\
100.0\end{array}$ \\
\hline $\begin{array}{l}\text { Do you approve the use of modern } \\
\text { methods of family planning? } \\
\text { Yes } \\
\text { No } \\
\text { Total } \\
X^{2}=\mathbf{1 1 . 5 3 8} \\
\text { d.f. }=\mathbf{1}, \mathbf{C}=\mathbf{0 . 1 0 7 ,} P=\mathbf{0 . 0 0 1}\end{array}$ & $\begin{array}{l}388 \\
112 \\
\mathbf{5 0 0}\end{array}$ & $\begin{array}{l}77.6 \\
22.4 \\
\mathbf{1 0 0 . 0}\end{array}$ & $\begin{array}{l}64 \\
500\end{array}$ & $\begin{array}{l}87.2 \\
12.8 \\
\mathbf{1 0 0 . 0}\end{array}$ & $\begin{array}{l}824 \\
176 \\
1000\end{array}$ & $\begin{array}{l}82.4 \\
17.6 \\
\mathbf{1 0 0 . 0}\end{array}$ \\
\hline $\begin{array}{l}\text { Do you intend to use a modern method } \\
\text { of family planning to prevent } \\
\text { pregnancy in the future? } \\
\text { Yes } \\
\text { No } \\
\text { Total } \\
X^{2}=12.511 \\
\text { d.f. }=1, C=0.112, P=0.000\end{array}$ & $\begin{array}{l}383 \\
117 \\
\mathbf{5 0 0}\end{array}$ & $\begin{array}{l}76.6 \\
23.4 \\
\mathbf{1 0 0 . 0}\end{array}$ & $\begin{array}{l}65 \\
\mathbf{5 0 0}\end{array}$ & $\begin{array}{l}87.0 \\
13.0 \\
\mathbf{1 0 0 . 0}\end{array}$ & $\begin{array}{l}818 \\
182 \\
\mathbf{1 0 0 0}\end{array}$ & $\begin{array}{l}81.1 \\
18.2 \\
\mathbf{1 0 0 . 0}\end{array}$ \\
\hline
\end{tabular}

\section{Age At First Childbirth And Attitude Towards Modern Family Planning Methods}

Coale (1973) argued that one of the three pre-conditions for a substantial decline of fertility within marriage is that fertility must be within the calculus of conscious choice. This means that potential parents must consider it an acceptable mode of thought and form of behavior to balance advantages and disadvantages before deciding to have another child. This conscious choice is an important factor that determines the attitude of an individual toward adoption of a family planning method. Table 4 shows that adolescent mothers attitude towards family planning although relatively good was lower in comparison with those of older mothers. The data show that 77.6 percent of adolescent mothers compared with 87.2 percent among older mothers approved of the use of modern methods of family planning. As expected, high proportion of adolescent mothers (76.6 percent), although relatively lower than the proportion of older mothers (87.0 percent) stated that they are willing to use a modern method of family planning to prevent pregnancy at anytime in the future.

\section{Discussion Of Findings And Recommendations}

The findings of this study had revealed the nexus between age at first birth and five variables in relation to family planning methods in the study location. These findings will be identified and discussed one after the other in the section. This study reveals that older mothers had relatively better knowledge about methods of family planning than adolescent mothers in Osun State, Nigeria. Specifically, 94.0 percent of older mothers as against 83.2 percent among adolescent mothers had knowledge about methods of family planning in the study 
area. The 2003 and 2008 NDHS reports also reveals better knowledge of pills, male condom and injectables among all women sampled in the study in Nigeria. Specifically, the 2003 report shows 60.4 percent knowledge of pills, 59.2 percent knowledge of male condom and 57.1 percent of knowledge of injectables among all women sampled (NPC, 2004:62; NPC, 2009: 68). Information on age of respondents and knowledge of modern contraceptive methods in Nigeria show low level of knowledge of family planning methods among adolescent women in ages 15-19 years compared with older mothers. Specifically, the knowledge of modern contraceptive methods was 61.6 percent among adolescents of ages 15-19 years compared with 83.4 percent among older women in age group 25-29 years in 2003 (NPC, 2004:64).

The study reveals that out of all the methods of family planning methods mentioned by the respondents, a much smaller proportion of adolescent mothers compared with older mothers reported ever used of any of the methods mentioned. Low levels of modern contraceptive use among adolescent mothers, despite their relatively high knowledge about these methods, may reflect lack of interest in the use of family planning methods among adolescents in the study area, especially immediately after commencement of childbearing. Data on specific methods of family planning ever used by adolescent mothers show that condom had the highest frequency of 55 respondents constituting 11.0 percent of adolescent mothers. This finding is similar to 2003 and 2008 NDHS reports on ever use of contraceptive methods by all women in Nigeria. According to these national reports, male condom has the highest frequency of 10.1 prevalence rate compared with 7.7 percent for pills, 5.5 percent for injectables, 1.6 percent for IUCD and 0.1 percent for implant (NPC, 2004:65; NPC, 2009).

It was discovered in the study that adolescent mothers consistently had low level of use in each of the contraceptive methods mentioned by the respondents during the survey. The low rate of contraceptive use among adolescent mothers suggests two important things. One, the high fertility rate observed among adolescent mothers may be a reflection of the low rate of adoption of contraception among this group of women in relation to older mothers in the State. Two, adolescent mothers in the study area may be at higher risk of contracting STIs including HIV relative to older mothers in the study area. This is because; the rate of condom use among adolescent mothers (8.0 percent) is very low in comparison with its use (21.2 percent) among older mothers in the State. Furthermore, many of the adolescent mothers married older, more sexually experienced and polygynous men within the community (Oyefara, 2011). This condition may predispose adolescent mothers to STIs including HIV more than older mothers in Osun State, Nigeria. Data on current use of contraceptive methods in 2008 NDHS are similar to the findings of this study. In particular, 2008 NDHS report shows general low rate of modern contraceptive methods among all women sampled in the study. For example, 3.4 percent of all women sampled are using condom, 2.0 percent are using pills, while 1.6 percent are using injectables (NPC, 2008:67).

The study further reveals that among small proportion of adolescent mothers that were currently using at least a method of contraception, 13.0 percent of them rely on instruction 
from their husbands/partners before they can adopt any method. In addition the study shows that many of older mothers enjoyed more support from their husbands (72.0 percent) compared to 63.3 percent among adolescent mothers when it comes to decision on whether to use a method of family planning. This information suggests that interpersonal communication between husbands and wives on the use of contraception was relatively higher among older mothers compared with adolescent mothers in the study area. The reasons for relatively poor communication between adolescent mothers and their spouses may be because many of them married older men as their husbands/partners and these older men were more likely to be polygynists with more than one wife who may not have opportunity of having deep discussion with any of their wives (since a polygynist must share his time among his wives) (Oyefara, 2011). It should be noted that inter-spousal communication and agreement among spouses is one of the factors that can bring about rapid fertility transition to any given country or community.

The study shows that adolescent mothers attitude towards family planning although relatively good was lower in comparison with those of older mothers. The data in the findings show that 77.6 percent of adolescent mothers compared with 87.2 percent among older mothers approved of the use of modern methods of family planning. As expected, high proportion of adolescent mothers (76.6 percent), although relatively lower than the proportion of older mothers (87.0 percent) stated that they are willing to use a modern method of family planning to prevent pregnancy at anytime in the future. As stated earlier, this information suggests that many of the adolescent mothers see the adoption of modern contraceptives as advantageous; consequently, their attitude and plan to use the modern contraceptive methods was very high, although lower than among older mothers. Thus the fertility transition that has just started in Yoruba society, Nigeria (NPB/WFS, 1984; FOS, 1992; NPC, 2000; 2004) may be quickly completed if both adolescent and older mothers in the region can be motivated, encouraged and made to see the benefits of the use of modern contraception in conjugal union.

In summary, findings in this study show that knowledge of contraceptive methods is gradually increasing among women in childbearing age in Osun State, Nigeria, but the proportion of women using modern or efficient methods of family planning is very low in the State. In addition, it is essential to note that the knowledge, ever used and current use of contraceptive methods is generally low among adolescent mothers compared with older mothers in the study location. Consequently, State governments, local and international non-state actors working on safe motherhood in Yoruba society need to reach adolescent mothers in-and-outside health institutions through community health workers with contraceptive methods messages and services in order to improve maternal health and reduce high population growth rate in Yoruba society.

\section{References}

Abdool-Karim, Q.; S.S. Abdool-Karim and E. Preston Whyte (1992), “Teenagers Seeking Condoms at Family Planning Services: A Providers Perspective". South African 
Medical Journal 82 (5): 360-362.

Adinma, J.I.B. and A.O. Okeke (1993), "The Pill: Perceptions and Usage among Nigerian Students." Advanced Contraceptions. 9: 345-346.

Agigian, A. (2010) "Baby Steps: How Lesbian Alternative Insemination is Changing the World. New York: Prestige.

Agyei, W.K.A. and E. J. Epema (1992), "Sexual Behaviour and Contraceptive Use among 15-24 Years Old in Uganda". International Family Planning Perspectives 18(1): 13 -17 .

Akin, A. (2007) "Emergence of Family Planning Programme in Turkey," in Robinson W.C. and J.A. Ross (eds.) The Global Family Planning Revolution: Three Decades of Population Policies and Programmes. Washington: Green Press Initiative. Pp. 85-102.

Alan Guttmacher Institute (1994), Sex and America's Teenagers. New York: AGI. P. 88.

Amazigo, U.; N. Silva; J. Kaufman and D.S. Obikeze (1997), "Sexual Activity and Contraceptive Knowledge and Use Among in-school Adolescents in Nigeria". International Family Planning Perspectives 23(1): 28-33.

Barganza, C.E.; C.A. Peyre and G. Aguilar (1989), "Sexual Attitudes and Behaviour of Guatemalan Teenagers: Considerations for Prevention of Adolescent Pregnancy". Adolescence 24 (94): 327-337.

Barker, G.K and S. Rich (1990), “Adolescent Fertility in Kenya and Nigeria: Final Reports for a Study Tour”. Center for Population Options, Population Crisis Committee.

Bell, S. (1992) "Birth Control," in The Boston Women's Health Book Collective: The New Our Bodies, Ourselves. New York: Touchstone.

Bhagat, P. (2004) India. Oxford Country Profile, $3^{\text {rd }}$ edition.

Bloom, D. \& D. Canning (2003) "Contraception and the Celtic Tiger," Economic and Social Review. Vol. 34. Pp. 229-247.

Boohene, E.; J. Tsodzai; K. Hardee-Cleaveland; S. Weir and B. Janowitz (1991), "Fertility and Contraceptive Use among Young Adults in Harare, Zimbabwe" Studies in Family Planning 22 (4): 264-271.

Coale, A. J. (1973), “The Demographic Transition". in the Proceeding of the International Population Conference (International Union for the Scientific Study of Population, 
Liege, Belgium) Pp. $53-72$.

Contraception Report (1995), "Contraception and Adolescents: Highlight from the NASPAG Conference" Contraception Report 6 (3): 4-11.

Daly, P.; M. Azefor and B. Nassah (1994), Safe Motherhood in Francophone Africa. Washington, D.C.; World Bank (HRO Working Paper). P. 2-17.

Delamo, E. (1988), Guide to Family Planning. New Edition. Ibadan: Spectrum Books Ltd. P.18.

Dixon-Mueller, R. (1993) "The Sexuality Connection in Reproductive Health," in Studies in Family Planning. Vol. 24. No. 5. Pp.269-282.

Federal Office of Statistics (1992), Nigeria Demographic and Health Survey 1990. Columbia, MD: DHS, IRD/Macro International.

Federal Republic of Nigeria (1988), National Policy on Population and Development for Unity, Progress and Self-reliance. Lagos, Federal Ministry of Heath.

Gupta, N. and L.C. Leite (1999), "Adolescent Fertility Behaviour: Trends and Determinants in Northeastern Brazil”. International Family Planning Perspectives 25 (3): 125-130.

Guttmacher, A.F. (1969) Birth Control and Love: The Complete Guide to Contraception and Fertility. London: Collies and McMillan.

Isiugo-Abanihe, U. C. (1996), "Women and Family Planning Practice in Nigeria". in E. A. Oke and B. E. Owumi (eds.) Readings in Medical Sociology Pp. 104 - 130 RDMS, Ibadan.

Isiugo-Abanihe, U.C. (2003) Male Role and Responsibility in Fertility and Reproductive Health in Nigeria. Ibadan: Centre for Population Activities and Education for Development.

Kau, M; C.O. Airhihenbuwa and B. Helm (1989), "Sexual Behaviour and Contraceptive Use by Adolescent Pupils in the Republic of Bophuthatswana". International Quarterly of Community Health Education 9 (1): 73-82.

Kiragu, K. (1991), "Factors Associated with Sexual and Contraceptive Behaviour among School Adolescents in Kenya". The 1989 Nakuru District Adolescent Fertility Survey, Final Report. Baltimore: John Hopkins University School of Hygiene and Public Health p. 38. 
Mahomed, K. and D. Masona (1991), “Adolescent Pregnancy - A prospective Survey of Contraceptive Knowledge and Reproductive Behaviour". Central African Journal of Medicine 37 910): 316-321.

Makinwa-Adebusoye, P. (1991), Adolescent Reproductive Health Behaviour in Nigeria: A Study of Five Cities. NISER Monograph Series, Number 3.

Martine, G. (1996), "Brazils Fertility Decline, 1965-95: A Fresh Look at Key Factors". Population and Development Review 22 (1): 47-75.

McCauley, A.P. and C. Salter (1995), "Meeting the Needs of Young Adults". Population Reports Series J, No. 41. Baltimore, John Hopkins School of Public Health, Population Information Programme, October. P. 43.

Mensch, B.; J. Bruce and M. Greene (1998), The Uncharted Passage: Girls'Adolescence on the Developing World. New York: Population Council. P. 115.

Mischell, D.R. (2007) "Family Planning: Contraception, Sterilization and Pregnancy Termination" Katz, V.L., Lentz, G.M., Lobo, R.A., and D.M. Gershen (eds.) Comprehensive Gynecology. $5^{\text {th }}$ Edition. Philadelphia: Mosby Elsevier, Chap. 14.

Morris, L. (1992), "Sexual Behaviour and Use of Contraception among Young adults: What Have We Learned from the Young Adult Reproductive Health Surveys in Latin America?". A Paper Presented at the $1^{\text {st }}$ Inter-African Conference on Adolescent Health, Nairobi, March 24-27. P. 31.

National Population Bureau and World Fertility Survey (1984), The Nigeria Fertility Survey 1981/82 Principal Report. Volume 1: Methodology and Findings.

National Population Commission \& ICF Macro (2009) Nigeria Demographic and Health Survey Abuja: NPC.

National Population Commission (1998), 1991 Population Census of the Federal Republic of Nigeria Analytical Report at the National Level. April 1998, Abuja, Nigeria.

National Population Commission (2000), Nigeria Demographic and Health Survey 1999. Calverton, Maryland: National Population Commission and ORC/Macro.

National Population Commission (2004), Nigeria Demographic and Health Survey 2003. Calverton, Maryland: National Population Commission and ORC/Macro.

Okonofua, F.E. (1995), "Factors Associated with Adolescent Pregnancy in Rural Nigeria". Journal of Youth and Adolescence 24: 419-438. 
Oyefara, J.L. (2011) Socio-Cultural Context of Adolescent Fertility in Yoruba Society: Insight from Osun State, Nigeria. Lagos: Concept Publications

Ozumba, B.C. and F.N Amaechi (1992) 'Awareness and Practice of Contraception among Female Students at the Institute of Management and Technology (IMT), Enugu". Public Health 106, Pp.459-461

Pachauri, S. (1996), "Reproductive Health: The Concept, Ideology, and Operational Issues". in Sengupta, J. and D. Shosh (eds.) Perspectives in Reproductive Health. New Delhi: New Age Publishers. Pp. 47-60.

Paxman, J.M and R.J. Zuckerman (1987), Laws and Policies Affecting Adolescent Health. Geneva: World Health Organization P. 310.

Sanhueza, H. (2007) "Family Planning in Chile: A Tale of the Unexpected," in Robinsin, W.C. \& J.A. Ross (eds.) The Global Family Planning Revolution: Three Decades of Population Policies and Programmes. Washington: Green Press Initiative. Pp. 105-129.

Schensul, S.L.; G. Oodit; J.J. Schensul; U. Bhowan and S. Ragobar (1993), Young Women, Work and AIDS-related Risk Behaviour in Mauritius". Washington, D.C. International Center for Research on Women. P. 4.

Tsui, M. \& A. Burke (2010) "Family Planning and the Burden of Unintended Pregnancies," Epidemiological Review. Vol. 32. No. 1. Pp. 152-74.

Weeks, J.R. (2002) Population: An Introduction to Concepts and Issues. California: Wadsworth.

Zabin, L.S.; J.F. Kantner and M. Zelnik (1979), "The Risk of Adolescent Pregnancy in the First Months of Intercourse”. Family Planning Perspectives 11(4): 215-222.

Zlider, V.M.; R. Gardner; S.O. Rutstein; L. Morris; H. Goldberg and K. Johnson (2003), "New Survey Findings: The Reproductive Revolution Continues". Population Reports Series M; NO. 17. Baltimore, John Hopkins Bloomberg School of Public Health, Population Information P. 29.

\section{Author's Profile}

Dr. John Lekan Oyefara has a B.Sc in Demography and Social Statistics from Obafemi Awolowo University, Ile-Ife, Nigeria. In addition, he obtained M.Sc and $\mathrm{PhD}$ in Sociology from the University of Ibadan, Nigeria. He specializes in demography, population studies, social research methods and statistics. His areas of research include fertility, mortality, 


\section{Macrothink}

Journal of Sociological Research

ISSN 1948-5468

migration, nuptiality, family planning, gender studies, and public and reproductive/family health including HIV/AIDS. He has worked for over fifteen years in the development sector with local and international organizations in Nigeria. He is currently a senior lecturer in the Department of Sociology, Faculty of Social Sciences, University of Lagos, Nigeria. 